\title{
Knowledge, attitude and practice of antenatal care among pregnant women attending antenatal clinic in a tertiary care hospital of Mathura, Uttar Pradesh, India
}

\author{
Parul Garg*, Divya
}

\begin{abstract}
Department of Obstetrics and Gynecology, K. D. Medical College, Hospital and Research Center, Mathura, Uttar Pradesh, India
\end{abstract}

Received: 05 May 2020

Accepted: 11 May 2020

\author{
*Correspondence: \\ Dr. Parul Garg, \\ E-mail: parulgarg.dr79@gmail.com
}

Copyright: () the author(s), publisher and licensee Medip Academy. This is an open-access article distributed under the terms of the Creative Commons Attribution Non-Commercial License, which permits unrestricted non-commercial use, distribution, and reproduction in any medium, provided the original work is properly cited.

\section{ABSTRACT}

Background: The objective of this study was to assess the knowledge, attitude and practice of antenatal care among pregnant women attending antenatal clinic in a tertiary care hospital and also to identify factors that are associated with non-usage of antenatal care.

Methods: The study was conducted on 150 pregnant women attending antenatal clinic in department of obstetrics and gynecology of K. D. Medical College and associated hospital of Mathura from September 2019 to December 2019. After obtaining consent, randomly selected pregnant women were given a pre-designed, structured questionnaire on socio-demographic variables, knowledge, attitude and practice towards antenatal care.

Results: In the present study, out of 150 respondents, $62.7 \%$ had knowledge and awareness regarding antenatal care. There was inadequate knowledge about frequency of antenatal visits with $59.3 \%$ subjects wanting to deliver in the hospital.

Conclusions: To improve effective utilization of ANC services, we need to bring behaviour changes, improve communication and quality of service delivery, along with effective monitoring and evaluation. Awareness should be developed in the community about the importance of registration for ANC, educating women about the detection of complications during pregnancy, importance of TT injection, IFA tablets and extra nutrition.

Keywords: Antenatal care, Attitude, Knowledge, Practice, Pregnant women

\section{INTRODUCTION}

Antenatal care is defined as a comprehensive antepartum care programme that involves co-ordinated approach to medical care and psychosocial support that optimally begins before conception and extends throughout antepartum period. Antenatal care (ANC) is a key strategy to decreasing maternal mortality in low resource setting. ANC clinics provide resources to improve nutrition and health knowledge and promote preventive health practices. A healthy mother brings forth a healthy baby. The health of the mother affects the overall growth and development of the child. The safe motherhood initiatives, a world wide effort was launched by the World Health Organization in 1987 which aimed to reduce the number of deaths associated with pregnancy and childbirth. Appropriate antenatal care (ANC) is one of the pillars of this initiative. Antenatal care is considered as a backbone of obstetrical services of any health of pregnant women and is the way in which maternal and fetal complications are detected and managed. Pregnant mothers contribute to a major vulnerable and priority group in any community, no less in India. According to the census 2011, maternal mortality rate in India accounts to an enormous figure of 212. ${ }^{1}$ Major causes include haemorrhage, obstructed 
labor, hypertension and other conditions. ${ }^{2}$ The reason being lack of proper antenatal care coverage and lack of awareness among mothers particularly from rural parts of India, contributing the major population, about the need of early registration and compliance with proper and regular antenatal check-ups.

To improve maternal health, barriers that limit access to quality maternal health services must be identified and addressed at all levels of the health system. Health knowledge is an important element to enable women to be aware of their health status and the importance of appropriate ANC. This study was conducted to determine the level of knowledge, attitude and practice related to antenatal care among pregnant women attending antenatal clinics in hospital set-up and to assess the awareness about their own health during pregnancy.

\section{METHODS}

This was a cross sectional study conducted by the department of obstetrics and gynecology at K. D. Medical College and Associated Hospital, Mathura from $1^{\text {st }}$ September 2019 to $31^{\text {st }}$ December 2019, to assess the knowledge, attitude and practice of antenatal care among 150 pregnant women attending antenatal clinic of department of obstetrics and gynecology.

\section{Inclusion criteria}

- All pregnant women attending antenatal clinic were interviewed.

\section{Exclusion criteria}

- Pregnant women who refused to take part in the study.

After obtaining the ethical committee approval, randomly selected pregnant women attending out-patient antenatal clinic who gave consent were included to participate in the study. The women were informed and explained about the study and in case of illiterate subjects, the nursing staff gave the guidance to obtain answers to questionnaire. A written pre-designed, structured questionnaire was given to the respondents which included socio-demographic details like age, religion, area of residence, type of family, education and occupation of subjects, parity and booking status of pregnant women.

The participants were also asked all types of questions which could help us to assess their knowledge, attitude and practice regarding antenatal care. The questionnaire enquired to assess awareness of ANC service and its importance among pregnant women. The questionnaire also addressed the reason of not using antenatal care among non-users of ANC service. Confidentiality of information provided was assured and maintained.

\section{Statistical analysis}

The responses were entered in excel spreadsheet and later analysed using SPSS software version 25 .

\section{RESULTS}

\section{Socio demographic characteristics}

A total of 150 antenatal women were successfully interviewed. The majority of the respondents were in the age group of 26-30 years, followed by 20-25 years. Regarding educational background $61(40.7 \%)$ attended primary education and $6.0 \%$ were illiterate. Quite a low proportion of the women received education above intermediate level. Regarding occupation most were housewives 87 (58\%) followed by unskilled workers 45 (30\%). Majority of mothers $67(44.7 \%)$ had numbers of children 1-2 (Table 1).

Table 1: Socio-demographic characteristics of subjects $(n=150)$.

\begin{tabular}{|c|c|c|c|}
\hline Characteristics & Category & Number & $\%$ \\
\hline \multirow{4}{*}{ Age in years } & $<20$ & 18 & $12.0 \%$ \\
\hline & $20-25$ & 42 & $28.0 \%$ \\
\hline & $26-30$ & 56 & $37.3 \%$ \\
\hline & $>30$ & 34 & $22.7 \%$ \\
\hline \multirow{2}{*}{ Religion } & Hindu & 118 & $78.7 \%$ \\
\hline & Muslim & 32 & $21.3 \%$ \\
\hline \multirow{2}{*}{ Residential area } & Rural & 134 & $89.3 \%$ \\
\hline & Urban & 16 & $10.7 \%$ \\
\hline \multirow{2}{*}{ Type of family } & Nuclear & 43 & $28.7 \%$ \\
\hline & Joint & 107 & $71.3 \%$ \\
\hline \multirow{6}{*}{$\begin{array}{l}\text { Education of } \\
\text { subject }\end{array}$} & Illiterate & 9 & $6.0 \%$ \\
\hline & Primary & 61 & $40.7 \%$ \\
\hline & High School & 37 & $24.7 \%$ \\
\hline & Intermediate & 28 & $18.7 \%$ \\
\hline & Graduate & 13 & $8.6 \%$ \\
\hline & Post graduate & 2 & $1.3 \%$ \\
\hline \multirow{3}{*}{$\begin{array}{l}\text { Occupation of } \\
\text { subject }\end{array}$} & Housewife & 87 & $58.0 \%$ \\
\hline & Skilled worker & 18 & $12.0 \%$ \\
\hline & $\begin{array}{l}\text { Unskilled } \\
\text { worker }\end{array}$ & 45 & $30.0 \%$ \\
\hline \multirow{2}{*}{ Booking status } & Booked & 47 & $31.3 \%$ \\
\hline & Unbooked & 103 & $68.7 \%$ \\
\hline \multirow{3}{*}{ Parity } & Nulliparous & 48 & $32.0 \%$ \\
\hline & $<3$ & 67 & $44.7 \%$ \\
\hline & $\geq 3$ & 35 & $23.3 \%$ \\
\hline
\end{tabular}

\section{Knowledge towards antenatal care service}

Table 2 shows the interviewed women's responses to the questions on knowledge regarding antenatal care. Majority of women 94 (62.7\%) ever heard about ANC service. Majority of antenatal women $52(34.7 \%)$ in the study considered single time ANC check-up sufficient throughout the course of pregnancy. From the respondents who knew about ANC, majority 73 (48.7\%) 
said ANC service was being given at health institution. Majority, 124 (82.7\%) antenatal women agreed to the fact that check-up during pregnancy reduces risk of complications during and after pregnancy. Among the woman who did not hear about ANC service, they did not hear about ANC service because of unavailability of media $23(41.1 \%)$, lack of information from health worker $18(32.1 \%)$ and lack of time 15 (26.8\%). Majority of antenatal women $111(74.0 \%)$ knew that ANC examination should be done within first 3 months. On interviewing for the place of delivery, $89(59.3 \%)$ were in favour of hospital delivery (Table 2).

Table 2: Knowledge about antenatal care among subjects.

\begin{tabular}{|c|c|c|c|}
\hline Variables & Category & Number & Percent $(\%)$ \\
\hline \multirow{2}{*}{ Do you know about ANC service? } & Yes & 94 & $62.7 \%$ \\
\hline & No & 56 & $37.3 \%$ \\
\hline \multirow{3}{*}{ Where is the service given? } & Health institution & 73 & $48.7 \%$ \\
\hline & Private clinic & 38 & $25.3 \%$ \\
\hline & Traditional attendant & 39 & $26.0 \%$ \\
\hline \multirow{4}{*}{$\begin{array}{l}\text { How many times mothers should get ANC } \\
\text { service in pregnancy? }\end{array}$} & Once & 52 & $34.7 \%$ \\
\hline & Twice & 49 & $32.7 \%$ \\
\hline & Three times & 28 & $18.6 \%$ \\
\hline & Four and above & 21 & $14.0 \%$ \\
\hline \multirow{2}{*}{$\begin{array}{l}\text { Should first ANC examination be done } \\
\text { within first } 3 \text { months? }\end{array}$} & Yes & 111 & $74.0 \%$ \\
\hline & No & 39 & $26.0 \%$ \\
\hline \multirow{2}{*}{$\begin{array}{l}\text { Does check-up during pregnancy reduces } \\
\text { risk of complications? }\end{array}$} & Yes & 124 & $82.7 \%$ \\
\hline & No & 26 & $17.3 \%$ \\
\hline \multirow{3}{*}{ Why did not know about ANC service? } & Unavailability of media & 23 & $41.1 \%$ \\
\hline & Lack of information from health worker & 18 & $32.1 \%$ \\
\hline & Lack of time to get information & 15 & $26.8 \%$ \\
\hline \multirow{2}{*}{ Should delivery happen at hospital/home? } & Hospital & 89 & $59.3 \%$ \\
\hline & Home & 61 & $40.7 \%$ \\
\hline \multirow{2}{*}{$\begin{array}{l}\text { Is it necessary to give Inj. Tetnus during } \\
\text { pregnancy? }\end{array}$} & Yes & 107 & $71.3 \%$ \\
\hline & No & 43 & $28.7 \%$ \\
\hline \multirow{2}{*}{$\begin{array}{l}\text { Does pregnant women need iron folic acid } \\
\text { supplements during pregnancy? }\end{array}$} & Yes & 94 & $62.7 \%$ \\
\hline & No & 56 & $37.3 \%$ \\
\hline \multirow{2}{*}{$\begin{array}{l}\text { Should pregnant women often get weight } \\
\text { and BP checked? }\end{array}$} & Yes & 88 & $58.7 \%$ \\
\hline & No & 62 & $41.3 \%$ \\
\hline
\end{tabular}

Table 3: Practice regarding antenatal care among subjects.

\begin{tabular}{|llll|}
\hline Variables & Category & Number & Percent $(\%)$ \\
\hline \multirow{2}{*}{ Have you followed ANC service? } & Yes & 81 & $54.0 \%$ \\
\cline { 2 - 4 } & No & 69 & $46.0 \%$ \\
\hline \multirow{3}{*}{ Where did get ANC service? (n=81) } & Health institution & 30 & $37.0 \%$ \\
\cline { 2 - 4 } & Private clinic & 14 & $17.3 \%$ \\
\cline { 2 - 4 } & Traditional attendant & 37 & $45.7 \%$ \\
\hline \multirow{2}{*}{ How many times did you get the service? } & One time & 31 & $38.3 \%$ \\
\cline { 2 - 4 } & Two times & 29 & $35.8 \%$ \\
\cline { 2 - 4 } & Three times & 16 & $19.7 \%$ \\
\cline { 2 - 4 } Where will delivery likely to happen? & Four and above & 5 & $6.2 \%$ \\
\cline { 2 - 4 } & Hospital & 91 & $60.7 \%$ \\
\hline
\end{tabular}

\section{Practice of ANC service}

Regarding practice, 81 (54\%) of antenatal women were following ANC service. Out of 81 respondents, 31 $(38.3 \%)$ had taken ANC service once, 29 (36.8\%) twice and only 5 (6.2\%) women had taken ANC service four and above times. Among the respondents, 91 (60.7\%) were likely to deliver at hospital and $59(39.3 \%)$ at home (Table 3). 
Table 4 shows the various reasons of not using ANC service among 69 non-users of ANC service. Majority 56 $(81.1 \%)$ were unaware of antenatal care service. Another common reason was that ANC service was available far away from home $42(60.9 \%)$ and $37(53.6 \%)$ had poor transportation facility. Out of $69,39(56.5 \%)$ of antenatal women thought that they were quite healthy and do not require ANC service (Table 4).

Table 4: Attitude among non-users of ANC service $(n=69)$.

\begin{tabular}{|ll|l|}
\hline Reason* & Number & Percent (\%) \\
\hline Unaware & 56 & $81.2 \%$ \\
\hline Thought I was healthy & 39 & $56.5 \%$ \\
\hline Check-up unaffordable & 22 & $31.9 \%$ \\
\hline $\begin{array}{l}\text { ANC service far away from } \\
\text { home }\end{array}$ & 42 & $60.9 \%$ \\
\hline $\begin{array}{l}\text { Family members unco- } \\
\text { operative }\end{array}$ & 25 & $36.2 \%$ \\
\hline Poor transportation facility & 37 & $53.6 \%$ \\
\hline Felt scared & 9 & $13.0 \%$ \\
\hline $\begin{array}{l}\text { Booking system user un- } \\
\text { friendly }\end{array}$ & 13 & $18.8 \%$ \\
\hline $\begin{array}{l}\text { Stigma due to cultural } \\
\text { beliefs }\end{array}$ & 28 & $40.6 \%$ \\
\hline *Multiple responses & & \\
\hline
\end{tabular}

\section{DISCUSSION}

Antenatal care allows for the management of pregnancy, detection and treatment of complications, and promotion of good health. In the present study, $65.3 \%$ of respondents belonged to age group 20-30 years. In study conducted by Rozliza et al, majority of the respondents (46.2\%) were from age group 20-29 years. ${ }^{3}$ Study conducted by Shirin $S$ et al, mean age of women was $33.5 \pm 10.4$ years. $^{4}$ In a study conducted by Alam AY et al, the mean age of women was $29.57 \pm 7.1$ years. ${ }^{5}$ Similar study conducted by Manas $\mathrm{P}$ et al, most of the respondents were more than 25 years. ${ }^{6}$ In present study, $89.3 \%$ were residents of rural areas and $10.7 \%$ from urban areas. Similarly, study conducted by Singh P et al, $63.7 \%$ respondent belongs to rural areas while $36.3 \%$ belongs to urban areas. $^{7}$ In the present study, $40.7 \%$ of subjects were educated up to primary and $24.7 \%$ subjects were educated till high school. On the contrary, study conducted by Rozliza et al, 42.3\% didn't received any primary or secondary education. In study conducted by Alam AY et al, 69.5\% subjects were illiterate. In present study, maximum respondents $58 \%$ were housewives. This is in line with the study conducted by Alam AY et al, $81.5 \%$ of respondents were housewives. Similar result was found in study conducted by Sonia Shirin et al, i.e. $96 \%$ were housewives.

In the present study about $60 \%$ of respondents had knowledge about ANC service, IFA tablet supplementation, TT injection and importance of weight and BP checked during pregnancy. In another study also, pregnant mothers were aware of injection TT and IFA supplementation. ${ }^{8}$ It is encouraging to note that pregnant women are aware of Inj. TT and IFA supplementation mainly because government health functionaries provide these. The knowledge regarding number of ANC visits was not adequate. The reason for the respondent's fair knowledge about ANC service was that illiterate women were very less. According to Becker et al. mother's education was the most consistent and important determinant of the use of child and maternal health service. ${ }^{9}$

A matter of concern was that nearly $40 \%$ of women with no antenatal care expressed total lack of knowledge about ANC service. Lack of concern about safe delivery was seen in $40.7 \%$ of antenatal women who did not feel to deliver in an institution and preferred to deliver at home. Low level of knowledge of antenatal well-being and less desire for hospital or assisted delivery was also observed in other lstudies. ${ }^{10}$ The reason regarding inadequate utilization of ANC services in this study like financial constraints, non-awareness, and non-availability of transport facilities are in agreement with the results of a similar study by Mumbare. ${ }^{11}$

It has been suggested that one of the best things that antenatal care could accomplish is to influence women to have an institutional delivery. An association between the use of antenatal care services and health facility delivery was observed in India and in other developing countries. An analysis based on data from India's first and second National Family Health Survey conducted was that mothers who received antenatal check-ups are two to five times more likely to give birth in medical institution than mothers who did not receive any antenatal check-up. In general, women prefer to deliver at home for reasons such as support, familiarity, tradition, belief that birth is considered a natural phenomenon for which an institutional delivery is not required. In this study, a majority of women with antenatal care planned an institutional delivery. It may, therefore, be possible to promote institutional delivery by promoting antenatal checkups and associated counselling.

\section{CONCLUSION}

To improve effective utilization of ANC services, authors need to bring behaviour changes, improve communication and quality of service delivery, along with effective monitoring and evaluation. Awareness should be developed in the community about the importance of registration for ANC, educating women about the detection of complications during pregnancy, importance of TT injection, IFA tablets and extra nutrition.

\section{ACKNOWLEDGMENTS}

Authors would like to thank all pregnant women who agreed to participate in this study. 
Funding: No funding sources

Conflict of interest: None declared

Ethical approval: The study was approved by the Institutional Ethics Committee

\section{REFERENCES}

1. Population Census 2011. Available at https://www.census2011.co.in. Accessed on $24^{\text {th }}$ April 2020.

2. Yohannes B, Tarekegn M, Paulos W. Mothers' utilization of antenatal care and their satisfaction with delivery services in selected public health facilities of Wolaita zone, Southern Ethiopia. IntJ Scien Technol Res. 2013;2(2):74-85.

3. Rozilza AM, Muhamad HJ. Knowledge, attitude and practices on antenatal care among Orang Asli women of Jempol, Negeri Sembilan, Malaysian. J Public Health Med. 2011;11(2):13-21.

4. Shirin S. Knowledge, attitude and practice of maternal health care amongst the married women in rural area of Bangladesh. Ibrahim Med Coll J. 2011;5(1):13-6.

5. Alam AY, Qureshi AA, Adil MM, Ali H. Comparative study of knowledge, attitude and practices among antenatal care facilities utilizing and non-utilizing women. J Pak Med Assoc. 2005;55(2):53-6.

6. Roy MP, Mohan U, Singh SK, Singh VK, Srivastava AK. Determinants of utilization of antenatal care services in rural Lucknow, India. J Family Med Prim Care. 2013;2(1):55.
7. Singh P, Yadav RJ. Antenatal care of pregnant women in India. Indian $\mathrm{J}$ Community Med. 2000;25(3):112.

8. Nomita C, Balwan SD, Indra K, Nirakar CS. Determinants of ANC utilization in rural areas of India: A cross-sectional study from 28 districts (An ICMR task force study). J Obstet Gynaecol India. 2006;56:47-52.

9. Becker S, Peters DH, Gray RH, Gultiano C, Black RE. The determinants of use of maternal and child health services in Metro Cebu, the Philippines. Health Transit Rev. 1993;3:77-89.

10. Mahadik KV, Deshpande KR. Survey of women of knowledge of cancer, antenatal well-being, attitudes and practices in rural, urban and urban slum area of Ujjain district in MP. J Obstet Gynaecol India. 2003;53:363-6.

11. Mumbare SS, Rege R. Antenatal care services utilization, delivery practices and factors affecting them in tribal areas of North Maharashtra. Indian J Community Med. 2011;36:287-90.

Cite this article as: Garg P, Divya. Knowledge, attitude and practice of antenatal care among pregnant women attending antenatal clinic in a tertiary care hospital of Mathura, Uttar Pradesh, India. Int J Reprod Contracept Obstet Gynecol 2020;9:2269-73. 